Results: Among the 1099 RA patients, 129 (11.7\%) overlapped with SS validated by positive anti-SSA or pathological minor salivary gland biopsy (MSGB). After propensity score matching based on their baseline characteristics, 126 of 129 RA-SS and 126 of 970 RA-noSS patients were statistically extracted. Overlapping SS was associated with a $29 \%, 26 \%, 18 \%, 22 \%$ lower probability of reaching remission in RA patients based on DAS28ESR, DAS28-CRP, SDAI, CDAI, respectively, which trend kept true for reaching low disease activity (LDA) either. Although overlapping SS had the most significant impact on ESR (HR $0.69,95 \% \mathrm{Cl} 0.61-0.79)$, other components assessing RA disease activity were also in jeopardy. When stratified by age, RA duration, RF and ACPA status, baseline DAS28-CRP, the trend remained.

Conclusion: Overlapping SS is associated with a lower probability of reaching target in RA patients, and should be regarded as one of the poor prognostic factors in the management of RA.

Table Hazard Ratios for Reaching Remission/Low disease activity and Individual Components in RA patients Associated with Overlapping SS

\begin{tabular}{ccc}
\hline $\begin{array}{c}\text { Unmatched cohort } \\
(n=1099)\end{array}$ & $\begin{array}{c}\text { Matched cohort } \\
(n=252)\end{array}$ & $\begin{array}{c}\text { Trimmed cohort } \\
(n=242)\end{array}$ \\
\hline
\end{tabular}

Remission Based on Composite Disease Activity Score

$0.71(0.62,0.82) \quad 0.74(0.64,0.85)$

DAS28-CRP $\quad 0.80(0.74,0.87) \quad 0.74(0.66,0.83) \quad 0.74(0.66,0.83)$

$\begin{array}{llll}\text { SDAI } & 0.82(0.74,0.91) & 0.82(0.70,0.94) & 0.83(0.72,0.97)\end{array}$

CDAI $\quad 0.77(0.70,0.86) \quad 0.78(0.67,0.91) \quad 0.78(0.67,0.91)$

$\begin{array}{llll}\text { Boolean } & 0.83(0.75,0.92) & 0.80(0.69,0.93) & 0.82(0.70,0.95)\end{array}$

Remission/LDA Based on Composite Disease Activity Score

DAS28-ESR $\quad 0.76(0.70,0.82) \quad 0.73(0.65,0.82) \quad 0.74(0.66,0.83)$

DAS28-CRP $0.80(0.74,0.86) \quad 0.76(0.68,0.84) \quad 0.75(0.68,0.84)$

SDAI $\quad 0.79(0.73,0.85) \quad 0.74(0.66,0.82) 0.74(0.66,0.82)$

$\begin{array}{llll}\text { CDAI } & 0.78(0.73,0.84) & 0.74(0.66,0.82) & 0.74(0.66,0.82)\end{array}$

Individual Components of Disease Activity Score

$28 \mathrm{SJC} \leq 1 \quad 0.83(0.77,0.89) \quad 0.77(0.69,0.85) \quad 0.76(0.68,0.84)$

28TJC $\leq 1 \quad 0.81(0.75,0.87) \quad 0.79(0.70,0.88) \quad 0.78(0.70,0.88)$

$\begin{array}{llll}P t G A \leq 1 & 0.81(0.74,0.89) & 0.82(0.71,0.94) & 0.82(0.72,0.95)\end{array}$

$\begin{array}{llll}\mathrm{PrGA} \leq 1 & 0.81(0.74,0.88) & 0.78(0.69,0.88) & 0.79(0.70,0.89)\end{array}$

ESR $\leq$ ULN $\quad 0.66(0.61,0.73) \quad 0.69(0.61,0.79) \quad 0.74(0.65,0.84)$

$\mathrm{CRP} \leq 1 \mathrm{mg} / \mathrm{dL} \quad 0.84(0.78,0.90) \quad 0.76(0.68,0.84) \quad 0.77(0.69,0.85)$

Disclosure of Interests: None declared

DOI: 10.1136/annrheumdis-2020-eular.715

\section{SAT0061 ROLE OF SHARED EPITOPE IN THE PROGNOSIS OF RHEUMATOID ARTHRITIS IN RELATION TO ACPA POSITIVITY}

J. Zhuo $^{1}$, J. Bryson ${ }^{1}$, Q. Xia ${ }^{1}$, N. Sharma ${ }^{2}$, S. Gao ${ }^{1}$, S. Lama ${ }^{1}$, M. E. Weinblatt ${ }^{3}$, N. Shadick ${ }^{3} .{ }^{1}$ Bristol-Myers Squibb, Lawrenceville, United States of America; ${ }^{2} \mathrm{Mu}$-Sigma, Bangalore, India; ${ }^{3}$ Brigham and Women's Hospital, Boston, United States of America

Background: The mechanistic association of $H L A-D R B 1$ alleles that code a "shared epitope" (SE) with rheumatoid arthritis (RA) is not yet clear. Previous data has suggested the carriage of $\mathrm{SE}$ is associated with the production of cyclic citrullinated peptide antibodies (anti-CCP) ${ }^{1}$ and severe $\mathrm{RA}^{2-4}$. The interrelationship among SE, anti-citrullinated protein antibody (ACPA) positivity and disease outcomes is not fully understood.

Objectives: To assess the RA prognosis associated with the carriage of SE, in relation to ACPA positivity.

Methods: Pts enrolled in a large RA registry, Brigham and Women's Hospital RA Sequential Study between March 2003 to June 2018, with known SE and ACPA status were included in the analysis. HLA-DRB1 SE status was determined by allele-specific polymerase chain reaction and DNA sequencing for most of the subjects and by GWAS-based imputation for the rest. Disease activity (DA) was measured at baseline (BL) and 1-year follow-up by DAS28(CRP), CDAI and SDAI. Pts were stratified by SE+ (1 or 2 SE alleles) and SE- ( 0 alleles) and ACPA status. We analyzed the relationship of SE with ACPA positivity and change in DA by a linear regression model separately. A mediation analysis was used to examine the mediating effect of ACPA on association between SE and change in DA.

Results: Out of 926 pts included in the analysis, $65.1 \%$ were $\mathrm{SE}+$, of whom $75.6 \%$ were ACPA+. In comparison, $51.7 \%$ were ACPA+ in SE- pts. SE+ pts were similar with SE- pts in age, gender, BMI and smoking status, but had longer disease duration, were more likely to be rheumatoid factor positive, have erosive disease and higher comorbidity burden irrespective of ACPA status. The differences were more pronounced if the pts were also ACPA+. Adjusting for BL differences, pts with SE 1 and 2 alleles (vs 0 ) had an odd ratio of $1.97(95 \% \mathrm{Cl}: 1.36-2.84 ; \mathrm{p}=0.0003)$ and $3.82(95 \% \mathrm{Cl}: 2.44$ $5.98 ; p<.0001)$ to be ACPA +, respectively. The regression analysis suggests that SE+ (vs SE-) pts had an average increase in DAS28 (CRP) of 0.22 $(p=0.033)$, CDAI of $2.07(p=0.045)$ and SDAI of $2.43(p=0.029)$ over a yea (Fig 1). Using a mediation analysis, the direct effect of SE+ account for $78.8 \%$ to $81.0 \%$ of total effect in the increase in DAS28 (CRP), CDAl and SDAI, and the indirect effect mediated by ACPA account for $19.0 \%$ to $21.2 \%$ (Table 1).

Figure 1. Linear Regression Model for SE Association with Change in Disease Activity

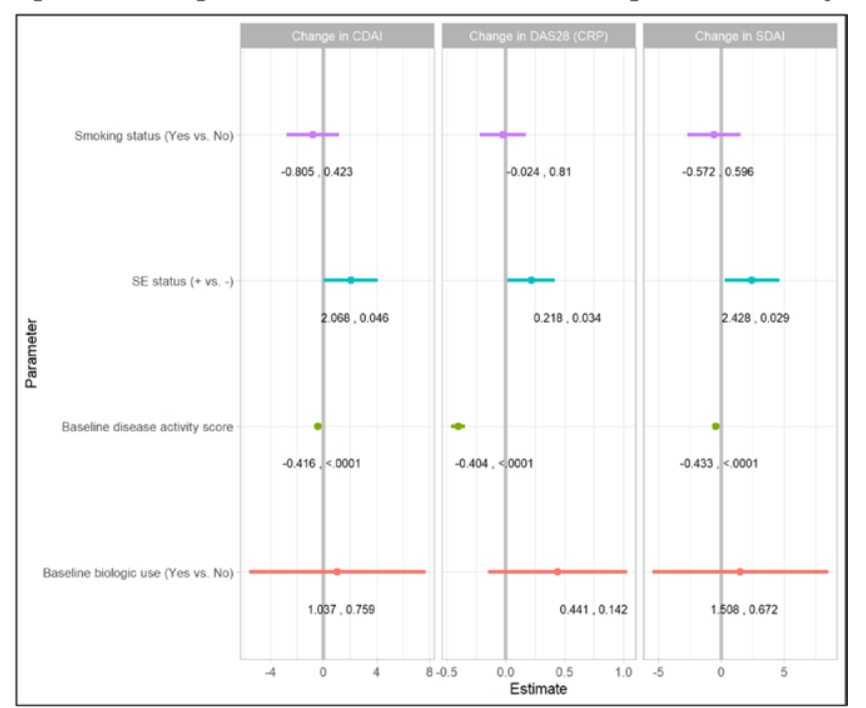

"Estimates, $p$-values are shown as data labels on the graphs; Change in disease activity $(D A)=($ follow-up DAbaseline DA); The above model is adjusted for age, gender, CCI, baseline DA, baseline biologic use, SE status and smoking status

Table 1. Mediation Analysis for SE and ACPA Association with Change in DA

\begin{tabular}{|c|c|c|c|c|c|c|}
\hline \multirow[t]{2}{*}{ Parameter } & \multicolumn{2}{|c|}{$\begin{array}{l}\text { Change in DAS28 } \\
\text { CRP }(\mathrm{N}=666)\end{array}$} & \multicolumn{2}{|c|}{$\begin{array}{l}\text { Change in CDAI } \\
\quad(\mathrm{N}=653)\end{array}$} & \multicolumn{2}{|c|}{$\begin{array}{l}\text { Change in SDAI } \\
\quad(\mathrm{N}=629)\end{array}$} \\
\hline & Estimate & P-value & Estimate & P-value & Estimate & P-value \\
\hline Total Effect of SE on DA change & 0.22 & 0.034 & 2.05 & 0.047 & 2.40 & 0.030 \\
\hline $\begin{array}{l}\text { Direct effect of SE on DA change } \\
\text { excluding mediation of ACPA }\end{array}$ & 0.17 & 0.101 & 1.57 & 0.140 & 1.89 & 0.098 \\
\hline $\begin{array}{l}\text { Indirect effect of SE on DA change } \\
\text { due to ACPA mediation and } \\
\text { interaction }\end{array}$ & 0.04 & 0.183 & 0.48 & 0.133 & 0.51 & 0.143 \\
\hline
\end{tabular}

The model is adjusted with other covariates: Age, Gender, Charlson comorbidity score; baseline biologic use, Smoking status, baseline DA, Interaction term ( $\left.A C P A^{*} S E\right)$

Conclusion: SE is strongly related to ACPA and a greater burden of disease in RA pts. In pts receiving standard treatments including biologics, SE is predictive of a greater increase in DA, which is partially mediated by the presence of ACPA.

\section{References:}

[1] Dayan I, et al., Arch of Rheumatology, 2010;25:012-018.

[2] Gregerson PK, et al, Arthritis Rheum. 1987;30:1205-1213.

[3] Turesson C, et al. Arthritis Res Ther. 2005;7:R1386-1393.

[4] Moreno I, et al. J Rheumatol. 1996;23:6-9.

Disclosure of Interests: Joe Zhuo Shareholder of: Bristol-Myers Squibb, Employee of: Bristol-Myers Squibb, Joshua Bryson Shareholder of: I own shares of Bristol-Myers Squibb Company, Employee of: I am a paid employee of Bristol-Myers Squibb Company, Qian Xia Shareholder of: I own shares of Bristol-Myers Squibb Company, Employee of: I am a paid employee of Bristol-Myers Squibb Company, Niyati Sharma Consultant of: I work as a consultant for Bristol-Myers Squibb Company, Sheng Gao Shareholder of: Bristol-Myers Squibb, Employee of: Bristol-Myers Squibb, Sonie Lama Shareholder of: I own shares of Bristol-Myers Squibb Company., Employee of: I am a paid employee 
of Bristol-Myers Squibb Company., Michael E. Weinblatt Grant/research support from: BMS, Amgen, Lilly, Crescendo and Sonofi-Regeneron, Consultant of: Horizon Therapeutics, Bristol-Myers Squibb, Amgen, Abbvie, Crescendo, Lilly, Pfizer, Roche, Gilead, Nancy Shadick Grant/research support from: Mallinckrodt, BMS, Lilly, Amgen, Crescendo Biosciences, and Sanofi-Regeneron, Consultant of: BMS

DOI: 10.1136/annrheumdis-2020-eular.4153

SATURDAY, 06 JUNE 2020

\section{Rheumatoid arthritis - comorbidity and clinical aspects}

\begin{tabular}{|l|l}
\hline SAT0062 & INCIDENCE OF STAPHYLOCOCCUS AUREUS \\
BACTEREMIA IN PATIENTS WITH RHEUMATOID \\
ARTHRITIS: A NATIONWIDE COHORT STUDY
\end{tabular}

S. Dieperink ${ }^{1}$, B. Glintborg ${ }^{1}$, L. B. Oestergaard ${ }^{2}$, M. Nørgaard ${ }^{3}$, T. Benfield ${ }^{4}$, F. Mehnert ${ }^{3}$, A. Petersen ${ }^{5}$, M. L. Hetland ${ }^{1} .{ }^{1}$ COPECARE and DANBIO, Rigshospitalet, Glostrup, Denmark; ${ }^{2}$ Cardiovascular Research Center, Gentofte Hospital, Copenhagen, Denmark; ${ }^{3}$ Department of Clinical Epidemiology, Aarhus University Hospital, Aarhus, Denmark; ${ }^{4}$ Department of Infectious Diseases, Hvidovre Hospital, Copenhagen, Denmark; ${ }^{5}$ Statens Serum Institut, Copenhagen, Denmark

Background: Staphylococcus aureus is a frequent cause of bacteremia (SAB) associated with high mortality and morbidity. Patients with rheumatoid arthritis (RA) are at increased risk of septic arthritis and prosthetic joint infection with $S$. aureus. Objectives: To assess the incidence rate (IR) of first-time $\mathrm{SAB}$ in patients with $\mathrm{RA}$ and to estimate the incidence rate ratio (IRR) of SAB with a general population cohort without RA serving as the reference.

Methods: Individuals with no prior history of SAB or RA were included consecutively from 31 December 1996, their 18th birthday or date of immigration, whichever came latest, and followed until first-time SAB, death, emigration or 31 December 2017, whichever came first. Information on RA diagnosis, vital status, age, sex, place of residence, comorbidities, medication and first-time SAB were achieved on an individual level through cross-linkage between five virtually complete Danish nationwide registries (Civil Registration System, National Patient Registry, Register of Medicinal Product Statistics, DANBIO rheumatology registry and the SAB database). We used Poisson regression to estimate adjusted IRRs overall and stratified by age and sex.

Results: In total, 6,127,150 individuals were included of whom 34,627 individuals developed RA. In the RA cohort, 228 first-time SAB events occurred during 283,186 person years (PY) of follow-up (IR 80.5/100,000 PY) compared with 25,268 events during $87,521,120 \mathrm{PY}$ of follow-up in the general population cohort (IR 28.9/100,000 PY). Median follow-up was 7.2 years (IQR 3.5-12.3) after RA diagnosis and 18.7 years (IQR 6.8-21) in the general population cohort. Individuals with RA who developed SAB were more often women, had an orthopaedic implant and had recent use of glucocorticoids compared with individuals with SAB without RA. (Table 1) IRs of SAB were higher among patients with RA compared with the general population in all age categories. The IRs increased with age and were higher in men, both in patients with RA and in the general population cohort. After adjustment, the IRR remained higher for individuals younger than 70 years with RA compared with the general population but was similar for older individuals. (Figure 1)

Conclusion: In this nationwide cohort with more than 25,000 observed first-time SAB events, patients with RA younger than 70 years old had a 1.5-2 times higher incidence rate compared with the general population. The significance of anti-rheumatic treatments on risk and the prognosis of SAB in patients with RA remain to be explored.

Acknowledgments: We wish to thank patient representative Pia Lüchau Pedersen

Disclosure of Interests: Sabine Dieperink: None declared, Bente Glintborg Grant/ research support from: Grants from Pfizer, Biogen and Abbvie, Louise Bruun Oestergaard: None declared, Mette Nørgaard: None declared, Thomas Benfield Grant/research support from: Pfizer, Novo Nordisk and GSK, Frank Mehnert: None declared, Andreas Petersen: None declared, Merete L. Hetland Grant/research support from: BMS, MSD, AbbVie, Roche, Novartis, Biogen and Pfizer, Consultant of: Eli Lilly, Speakers bureau: Orion Pharma, Biogen, Pfizer, CellTrion, Merck and Samsung Bioepis

DOI: 10.1136/annrheumdis-2020-eular.223
Table 1 Characteristics of patients with RA at time of RA diagnosis and patients with $S A B$ with/without $R A$ at time of $S A B$ diagnosis

\begin{tabular}{lccc}
\hline Characteristic, $\mathrm{n}(\%)$ & At RA diagnosis & At first-time SAB \\
\hline & $\mathrm{RA}(\mathrm{n}=34,627)$ & $\mathrm{RA}(\mathrm{n}=228)$ & Non-RA $(\mathrm{n}=25,268)$ \\
\hline Age, years (IQR) & $59.8(48.8-70.3)$ & $71.8(62.3-79.2)$ & $69.7(57.7-79.7)$ \\
Female, \% & $69 \%$ & $59 \%$ & $38 \%$ \\
Diabetes mellitus & $2,467(7.1 \%)$ & $51(22.4 \%)$ & $5,678(22.5 \%)$ \\
Heart failure & $1,018(2.9 \%)$ & $42(18.4 \%)$ & $4,718(18.7 \%)$ \\
Liver disease & $454(1.3 \%)$ & $12(5.3 \%)$ & $2,189(8.7 \%)$ \\
Chronic obstructive pulmonary disease & $1,677(4.8 \%)$ & $36(15.8 \%)$ & $3,412(13.5 \%)$ \\
Cancer & $2,124(6.1 \%)$ & $60(26.3 \%)$ & $6,742(26.7 \%)$ \\
HIV & $11(0.0 \%)$ & $0(0 \%)$ & $127(0.5 \%)$ \\
Solid organ transplant & $8(0.0 \%)$ & $0(0 \%)$ & $357(1.4 \%)$ \\
Alcohol abuse & $642(1.9 \%)$ & $12(5.3 \%)$ & $3,356(13.3 \%)$ \\
Chronic dialysis & $29(0.1 \%)$ & $11(4.8 \%)$ & $2,256(8.9 \%)$ \\
Orthopedic implant & $3,807(11.0 \%)$ & $89(39.0 \%)$ & $5,422(21.5 \%)$ \\
Cardiac or vascular implant & $731(2.1 \%)$ & $18(7.9 \%)$ & $1,940(7.7 \%)$ \\
Glucocorticoid (0-90 days prior) & $7,062(20.4 \%)$ & $99(43.4 \%)$ & $2,911(11.5 \%)$ \\
Invasive surgery (0-30 days prior) & $1,962(5.7 \%)$ & $62(27.2 \%)$ & $8,451(33.5 \%)$ \\
\hline
\end{tabular}

\section{Figure 1}

Age and sex stratified first-time $S$. aureus bacteremia (SAB) cases, incidence rates (IR) and comorbidity-adjusted incidence rate ratios (IRR) of SAB in patients with rheumatoid arthritis (RA) compared with the general population

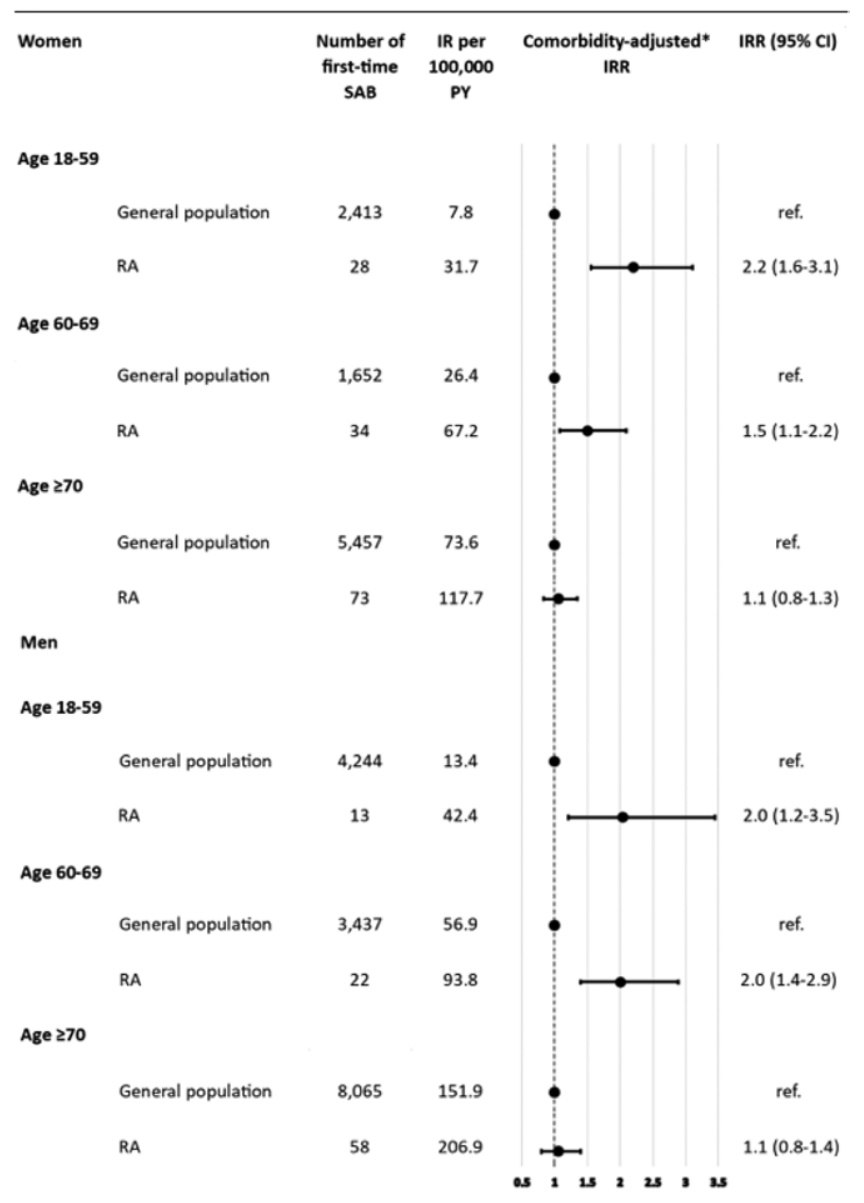

* Results from Poisson regression model. Adjusted for age (as a continuous variable), calendar year (3year intervals), diabetes mellitus, alcohol abuse, chronic dialysis, cancer, orthopedic implants, cardiac or vascular implants, chronic obstructive pulmonary disease and chronic heart failure. Follow-up time was split according to exposure status of these time-dependent covariates

\section{SAT0062 THE COMBINED VACCINATION SCHEME AGAINST STREPTOCOCCUS PNEUMONIAE IS EFFECTIVE IN RHEUMATOID ARTHRITIS PATIENTS TREATED WITH DMARD: DATA FROM BIOBADASER 3.0}

S. C. Rodriguez-García ${ }^{1}$, C. Sánchez-Piedra ${ }^{2}$, R. Castellanos-Moreira ${ }^{3}$, D. RuizMontesinos ${ }^{4}$, V. Hernandez ${ }^{3}$, M. Pombo ${ }^{5}$, F. Sánchez-Alonso ${ }^{2}$, L. Carmona ${ }^{6}$ J. J. Gómez-Reino ${ }^{5}$ on behalf of BIOBADASER Study group. ${ }^{1} \mathrm{Hospital}$ de La 